\begin{tabular}{|c|c|c|c|c|}
\hline Confidence levels in: & Number of trainees & Mean Improvement (SD) & $\%$ Improvement & $P$ Value \\
\hline Knowing the indications for thoracoscopy & Pre=11, Post=11 & $1.27(0.65)$ & 31.82 & 0.004 \\
\hline Knowing the contra-indications for thoracoscopy & Pre=11, Post=11 & $1.36(0.67)$ & 34.09 & 0.004 \\
\hline Consenting the patient and quoting accurate complication rates & Pre=11, Post=11 & $1.36(0.5)$ & 34.09 & 0.002 \\
\hline Being aware of the complications of thoracoscopy & Pre $=10$, Post $=11$ & $1.3(0.67)$ & 32.50 & 0.006 \\
\hline Knowing the limits of safe conscious sedation and the complications & Pre=11, Post $=11$ & $1.54(0.93)$ & 38.64 & 0.004 \\
\hline Technical ability in handling the thoracoscopy equipment & Pre=11, Post=11 & $2.54(0.82)$ & 63.64 & 0.004 \\
\hline Knowing the indications for IPC insertion & Pre $=10$, Post $=11$ & $2.1(1.1)$ & 52.50 & 0.007 \\
\hline Technical ability in performing an IPC insertion & Pre $=11$, Post $=11$ & $2.45(1.69)$ & 61.36 & 0.007 \\
\hline
\end{tabular}

the large airways. Knowledge testing was carried out using a preparing the patient metal algorithm taught during the course. The data generated was recorded on an assessment proforma entitled the Basic Bronchoscopy Simulation Assessment Tool (BBSAT).

Results Statistically significant confidence levels were found in 9 domains in all trainees after the course. Confidence levels fell significantly after assessment in the majority of domains (Table1). Dexterity was retained at assessment, but a small fall in anatomical knowledge was demonstrated in Anaesthetic and Respiratory trainees. MCQ knowledge also showed a general decrease at assessment. The average BBSAT score was 67.2/72 (93\%) indicating that all trainees had retained the basic level of skills required to perform bronchoscopy in a simulated environment. Conclusion Overall, skills and knowledge are retained to a level required to perform bronchoscopy in a simulated environment, however confidence of trainees is significantly affected at assessment two months later. We propose that trainees are provided with mandatory bronchoscopy simulation training accompanied by assessment to ensure that skills are retained. We believe that basic bronchoscopy should be mastered before diagnostic bronchoscopy is broached; hence the use of a mastery assessment similar to the BBSAT may helpful in guiding simulation-based assessment.

\section{P70 MANAGEMENT OF PLEURAL EFFUSIONS: ARE HEALTHCARE PROFESSIONALS ADEQUATELY TRAINED?}

CL Ross, R Dimock, A Chotai, R Meeajan, T Wan, L Finney, SL Elkin; Imperial College Healthcare NHS Trust, London, UK

\subsection{6/thoraxjnl-2013-204457.220}

Introduction and Objectives Management of pleural effusions is evolving with the introduction of a Best Practice Tariff for unilateral effusions and increasing use of thoracic ultrasound. However, transitions have been slow to filter through to clinical practice. This improvement project investigated the current management of pleural effusions within our Trust.

Methods We conducted: 1) An audit of all procedures for pleural effusions between 01.09.12 and 30.11.12; 2) A survey of junior doctors to establish their training provision, current practice and knowledge; and 3) A survey of acute medicine, respiratory, cardiothoracic and oncology nurses who regularly care for patients with effusions.

Results The audit reviewed 52 chest drains and 20 aspirations across 3 sites. Documentation of consent occurred in 39\% of cases. Ultrasound was used in $79 \%$ of drains, but $26 \%$ of cases still used a remote ' $\mathrm{X}$ marks the spot' approach. $27 \%$ of procedures were done out-of-hours and $34 \%$ of patients waited over 12 hours for a chest x-ray following drain insertion. 61 junior doctors responded to the survey: $44 \%$ did not use sterile gowns when inserting drains; $11 \%$ did not use sterile gloves. No medical doctors had acquired level 1 ultrasound competence. Of the
31 nurses surveyed: $19 \%$ did not know the significance of a 'bubbling' drain; 39\% did not know what 'swinging' indicated; $48 \%$ did not equate closing a 3-way tap with clamping a drain; and $26 \%$ were not aware chest drain bottles should be kept below the insertion point. $54 \%$ had never received any training regarding chest drain management. $45 \%$ of doctors and $58 \%$ of nurses were unaware of local guidelines.

Conclusions It is unlikely our findings are grossly different to practice in other inner city Trusts. With high staff turnaround, regular training for those caring for people with pleural effusions is clearly needed. Training should focus on aspects of patient safety such as image-guidance, aseptic technique and drain management. This study has led to the introduction of new local guidelines and pathways, creation of a pleural procedure kit to include aseptic equipment, implementation of an effusion bundle, and training sessions for doctors and nurses.

\section{P71 TRAINING OF JUNIOR DOCTORS INTO THORACIC ULTRASOUND AND PLEURAL PROCEDURES-IMPACT OF A DEDICATED RESPIRATORY CONSULTANT -SUPERVISED ADVANCED NURSE PRACTITIONER-SUPPORTED SESSION}

F Thaivalappil, D O'Neill, A lonescu; Royal Gwent Hospital, Newport, UK

\subsection{6/thoraxjnl-2013-204457.221}

The BTS made recommendations on pleural services. In order to stream-line the elective pleural procedures (other than thoracoscopy) a mid-week session was initiated on the pleural unit at a teaching hospital providing for over 500,000.

Aims To review the impact of a mid-week dedicated pleural session (DPS) Consultant -led and advanced nurse practitioner (ANP) -supported on the ward -based thoracic ultrasound (US) and pleural procedure training of respiratory trainees and impact on other hospital services.

Methods This is an analysis of data collected prospectively at the time of the US and procedures over 1 year. US referred to radiology were obtained from a search on radiology database. Changes over a period of six months after the DPS was started were assessed against the six months before. SPSS programme and $\mathrm{Chi}^{2}$ test were used.

Results The numbers of US and procedures over 6 months was similar before and after the DPS ( $\mathrm{N}=297$ vs. 260). Procedures performed on a Monday were less after DPS $\left(\mathrm{Chi}^{2}=9.21, \mathrm{p}<\right.$ 0.01), but not for Thursdays and Fridays.

Procedures done by trainees under Consultant supervision increased with the DPS $\left(\mathrm{Chi}^{2}=5.45, \mathrm{p}=0.019\right)$, so did those performed by the ANP (from 25 to 66 procedures, $\mathrm{Chi}^{2}=23.4$, $\mathrm{p}<0.001)$.

The proportion of chest drains inserted out of hours was $1.8 \%$ all were done by trained respiratory juniors. $20 \%$ US and procedures were referred by other departments. 
US performed in radiology were $4 \%, 0.7 \%$ referred by the respiratory teams and the rest mainly from intensive care.

No major complication (death, organ injury, empyema, bleeding) occurred. All specialist registrars reached level 1 US.

Conclusion A dedicated mid-week pleural procedures session improved the training and supervision for respiratory trainees and provides a safe service.

This session reduced the burden of procedures performed on Mondays but was not sufficient to reduce the numbers performed before the weekend. An additional session is planned for Fridays.

A level 1 thoracic US trained ANP assisted the training of juniors and the provision of service.

Most pleural US and procedures are performed on the pleural unit, which reduced the burden on radiology department.

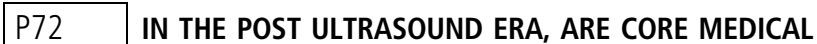 TRAINEES STRUGGLING TO GET EXPERIENCE IN CHEST DRAIN INSERTION?}

JL Connor, P Griffiths, M Gautam, A Youzguin; Southport District General Hospital, Southport, United Kingdom

\subsection{6/thoraxjnl-2013-204457.222}

Introduction In the UK, upon completion of Core Medical Training (CMT), procedural independence is expected for pneumothorax drains and is desirable for pleural effusions. In 2009, prompted by a National Patient Safety Agency report, a local guideline was introduced in our hospital aiming to reduce intercostal chest drain (ICD) complications for effusions by formalising training, increasing supervision and utilising bedside ultrasound scan (USS). Consequently, rates of adverse events have significantly been reduced. This raises the question, however, have such measures reduced the procedural exposure for CMT doctors.

We aimed to compare the numbers of ICDs inserted by CMT doctors for effusions in 2008 and 2012. The numbers of ICDs inserted by CMTs for pneumothorax compared to effusion in 2012 was also examined.

Methods All patients who received an ICD for effusion or pneumothorax in 2012 and for effusion in 2008 were retrospectively reviewed. We reviewed grade of doctor performing ICD insertion, supervision, and use of USS (for effusion).

Results CMTs inserted significantly less ICDs for effusions in $2012(10 / 30,33 \%)$ compared to $2008(20 / 39,51 \%) \mathrm{z}=1.75$, $\mathrm{p}=0.04$. Supervision rates increased from $73 \%$ in 2008 to $100 \%$ in 2012 . Bedside USS was used in $100 \%$ of effusionrelated ICDs in 2012 compared to $0 \%$ in 2008.

In 2012 alone, CMTs inserted significantly fewer ICDs for pneumothorax $(4 / 28,14 \%)$ compared to effusions $(10 / 30,33 \%) \mathrm{z}=$ $1.69, \mathrm{p}=0.046$. A\&E doctors inserted the majority of ICDs for pneumothorax $(15 / 28,53 \%)$, whilst a Respiratory Registrar/Consultant inserted the majority of ICDs for effusions (13/30, 43\%).

Conclusions Since 2008, there has been a significant reduction in ICD insertions by CMTs. The majority of ICD insertions for pleural effusions being performed using USS by appropriately trained respiratory physicians may explain this. The significant fall in the number of ICD insertions by CMTs for pneumothorax (where USS guidance is not required) however, suggests that overall ICDs are becoming a specialist procedure rather than a generic competency. Trainees are at risk of not fulfilling their competency requirements and this poses the question should procedural training and curriculum objectives be readdressed in light of the growing need for USS experience.

\section{P73 THE CREATION OF A SIMULATED PAN-DEANERY MEDICAL THORACOSCOPY AND INDWELLING PLEURAL CATHETER COURSE}

${ }^{1} \mathrm{~F}$ Chowdhury, ${ }^{2} \mathrm{~N}$ Chaudhuri, ${ }^{3} \mathrm{~S}$ Renshaw, ${ }^{1} \mathrm{~S}$ Pathmanathan, ${ }^{4} \mathrm{~J} \mathrm{Hogg,}{ }^{3} \mathrm{~J}$ Hill, ${ }^{4} \mathrm{P}$ Blaxill, ${ }^{5}$ T Rogers, ${ }^{1} \mathrm{~J}$ Kastelik; ${ }^{1}$ Hull Institute of Learning and Simulation, Hull, East Yorkshire; ${ }^{2}$ United Hospitals of South Manchester, Manchester, UK; ${ }^{3}$ Sheffield Teaching Hospitals NHS Foundation Trust, Sheffield, South Yorkshire; ${ }^{4}$ Pinderfields Hospital NHS Trust, Wakefield, UK; ${ }^{5}$ Doncaster and Bassetlaw Hospitals NHS Trust, Doncaster, UK

\subsection{6/thoraxjn-2013-204457.223}

Introduction Medical thoracoscopy (MT) and indwelling pleural catheter (IPC) insertion are becoming increasingly utilised for the purposes of diagnostic and therapeutic intervention in pleural disease. We are at the cusp of a paradigm shift towards the expansion of hospital services within Respiratory departments nationally, to accommodate the ever increasing demand of advances in medical treatment. Few courses are available that train respiratory doctors nationally. Health Education Yorkshire and The Humber have designed a novel simulation course to teach trainees the skills of MT and IPC insertion.

Methods A respiratory simulation team involving three consultants and a registrar used an approach similar to that described by Tjiam et al. 2012 using a cognitive task analysis (CTA) and the four component instructural design (4C/ID) as the basis of the course. The blueprint was created which broke down the tasks involved. The course consisted of four lectures and a demonstration followed by four stations including medical thoracoscopy; trocar and chest drain insertion; IPC insertion and a multiple choice questionnaire (MCQ). Peer review of the lectures and also the MCQ was also carried out. All consultants from specialist lung cancer services across the region were invited to be faculty on the course. Pre and post course Likert scale questionnaires were used to assess confidence levels.

Results Statistically significant improvements in confidence levels were achieved in all 8 domains, particularly in technical ability

\begin{tabular}{|c|c|c|c|c|}
\hline Confidence levels in: & $\begin{array}{l}\text { Number } \\
\text { of } \\
\text { trainees }\end{array}$ & $\begin{array}{l}\text { Mean } \\
\text { Improvement } \\
\text { (SD) }\end{array}$ & $\begin{array}{l}\% \\
\text { Improvement }\end{array}$ & $\begin{array}{l}P \\
\text { Value }\end{array}$ \\
\hline $\begin{array}{l}\text { Knowing the indications } \\
\text { for thoracoscopy }\end{array}$ & $\begin{array}{l}\text { Pre=11, } \\
\text { Post=11 }\end{array}$ & $1.27(0.65)$ & 31.82 & 0.004 \\
\hline $\begin{array}{l}\text { Knowing the } \\
\text { contra-indications for } \\
\text { thoracoscopy }\end{array}$ & $\begin{array}{l}\text { Pre=11, } \\
\text { Post=11 }\end{array}$ & $1.36(0.67)$ & 34.09 & 0.004 \\
\hline $\begin{array}{l}\text { Consenting the patient } \\
\text { and quoting accurate } \\
\text { complication rates }\end{array}$ & $\begin{array}{l}\text { Pre }=11 \\
\text { Post }=11\end{array}$ & $1.36(0.5)$ & 34.09 & 0.002 \\
\hline $\begin{array}{l}\text { Being aware of the } \\
\text { complications of } \\
\text { thoracoscopy }\end{array}$ & $\begin{array}{l}\text { Pre }=10 \\
\text { Post }=11\end{array}$ & $1.3(0.67)$ & 32.50 & 0.006 \\
\hline $\begin{array}{l}\text { Knowing the limits of } \\
\text { safe conscious sedation } \\
\text { and the complications }\end{array}$ & $\begin{array}{l}\text { Pre }=11 \\
\text { Post }=11\end{array}$ & $1.54(0.93)$ & 38.64 & 0.004 \\
\hline $\begin{array}{l}\text { Technical ability in handling } \\
\text { the thoracoscopy equipment }\end{array}$ & $\begin{array}{l}\text { Pre }=11 \\
\text { Post }=11\end{array}$ & $2.54(0.82)$ & 63.64 & 0.004 \\
\hline $\begin{array}{l}\text { Knowing the indications } \\
\text { for IPC insertion }\end{array}$ & $\begin{array}{l}\text { Pre=10, } \\
\text { Post=11 }\end{array}$ & $2.1(1.1)$ & 52.50 & 0.007 \\
\hline $\begin{array}{l}\text { Technical ability in } \\
\text { performing an IPC insertion }\end{array}$ & $\begin{array}{l}\text { Pre }=11 \\
\text { Post }=11\end{array}$ & $2.45(1.69)$ & 61.36 & 0.007 \\
\hline
\end{tabular}

